\section{SP3-8 MYOCARDIAL INFARCTION AND SOCIO-ECONOMIC CRISIS IN RUSSIA 1977-2006}

doi:10.1136/jech.2011.1429760.8

$1,2 \mathrm{~V}$ Gafarov, ${ }^{*} \mathrm{~A}$ Gafarova. ${ }^{1}$ Collaborative laboratory of Epidemiology Cardiovascular Diseases Siberian Branch of the Russian Academy of Medical Sciences, Novosibirsk, Russia; ${ }^{2}$ Institute of Internal Medicine Siberian Branch of the Russian Academy of Medical Sciences, Novosibirsk, Russia

Background To investigate myocardial infarction (MI) morbidity, mortality and death rates between 1977 and 2006, and their determinants in a high-risk population in Russia.

Materials and Methods The WHO programs "Register of Acute Myocardial Infarction", "MONICA".

Results During 30 years (1977-2006), 23137 MI cases were registered, of which 7630 were fatal. The 30 -year MI morbidity rates were relatively stabile, with the exception of increases in 1988, 1994, 1998 and decreases in 2002-2004 and 2006. Mortality rates were also stable with the exception of increases in 1988, 1994, 1998, and 2002-2005 and decreases in 1977-1978 and 2006. Increases in anxiety levels were recorded by three screening studies in 1984, 1988, 1994 which roughly correspond with increases in MI morbidity and mortality rates.

Conclusions Our results have shown the MI morbidity in population (Novosibirsk) in Russia to be among the highest in the world. They may be markers of the increasing social and economic instability in the country.

\section{SP3-9 AN EPIDEMIOLOGICAL STUDY ON HEALTH PROVIDER PRACTICES AND THE FACTORS INFLUENCING THEM IN RURAL AREA OF UDUPI TALUK, KARNATAKA, INDIA}

doi:10.1136/jech.2011.1429760.9

K Kulothungan, ${ }^{*}$ N Kondagunta, A Shetty, A Kamath. SRM University, Tiruchirapalli, Tamilnadu, India

Objectives To know the range of services provided by the various health providers, to study their criteria for determining fees for the services provided, to understand their barriers in providing the services and to study the factors responsible for their job satisfaction and dissatisfaction in rural areas of Udupi taluk, Karnataka state, India. Materials and Methods A cross sectional study was conducted in rural areas of Udupi taluk between September 2007 and October 2008 among 150 rural practitioners. Data were collected by interviewing the practitioners using pre-tested, semi-structured questionnaire. The quantitative data were analysed using SPSS 14.0. The qualitative data were collected using In-depth interview technique. Results and Conclusion Provision of preventive health services and participation in national programmes by the private practitioners was found to be inadequate. Practitioners determine their fees based on the economic status of the patient and the cost of medicines dispensed. Inadequate and irregular income is the major barrier for both government and private sector doctors and most of them were moderately satisfied with their job.

\section{SP3-10 PSYCHOSOCIAL FACTORS AND ARTERIAL HYPERTENSION IN MALES AGED 25-64 YEARS IN RUSSIA (EPIDEMIOLOGICAL RESEARCH)}

doi:10.1136/jech.2011.142976o.10

\footnotetext{
1,2V Gafarov, ${ }^{*} 1,2 \mid$ Gagulin, ${ }^{1,2} \mathrm{~A}$ Gafarova. ${ }^{1}$ The Collaborative laboratory of Epidemiology of Cardiovascular Diseases Siberian Branch of Russian Academy of Medical Sciences, Novosibirsk, Russia; ${ }^{2}$ Institute of Internal medicine the Siberian Branch of Russian Academy of Medical Sciences, Novosibirsk, Russia
}

Background To study connection of arterial hypertension (AH) with psychosocial factors (PF) at men in the age of 25-64 years in Russia.
Materials and Methods A random representative sample of males (a total of 2149 individuals) aged 25-64 years from the city Novosibirsk was examined (screening of the WHO "MONICApsychosocial" program ("MOPSY"), 1984, 1988, 1994 yr.). Depression (D), vital exhaustion (VE), hostility $(\mathrm{H})$, sleep disturbance; test Berkman-Syme (social support-index of close contacts (ICC), index of social connections (SNI)); Spilberger's test for estimation personal anxiety (PA) were used. For AH accepted the arterial pressure $>140 / 90 \mathrm{~mm} \mathrm{Hg}$.

Results Determined, that persons with $\mathrm{AH}$ have tendencies: (1) in higher parameters of "average", "bad" sleep; (2) in lower values of indexes of social support-(a low ICC with AH-65.1\%, $\mathrm{p}<0.01$ ) and SNI (low SNI with AH-45.1\%, p<0.05) (3) in increase of a parameter of PA (with $\mathrm{AH}-52.3 \%, \mathrm{p}<0.05$ ). Authentic connection $\mathrm{AH}$ is precisely determined with: (1) education, achieving a maximum of distinctions at an initial education (initial: with $\mathrm{AH}-25.1 \%, \mathrm{p}<0.05$ ) (2) an professional level (working trades $-10.7 \% \mathrm{p}<0.001$ ) (3) with VE (a high level of VE: with $\mathrm{AH}-16.6 \%, \mathrm{p}<0.05$ ) (4) with $\mathrm{D}$ (with $\mathrm{AH}-55.3 \%, \mathrm{p}<0.05)$. In too time at hostility of distinctions between groups it is not determined.

Conclusion Received results testify to interrelation $\mathrm{AH}$ in a population with psychosocial factors and once again emphasise importance of their correction.

\section{SP3-11 TEN-YEAR TRENDS IN THE HEALTH OF BRAZILIAN ELDERLY: EVIDENCES FROM A NATIONALLY REPRESENTATIVE HEALTH SURVEY (PNAD 1998, 2003, 2008)}

doi:10.1136/jech.2011.1429760.11

${ }^{1,2} \mathrm{M}$ F Lima-Costa, ${ }^{1} \mathrm{D}$ L Matos, ${ }^{2} \mathrm{~V}$ P Camargos, ${ }^{3} \mathrm{~J}$ Macinko. ${ }^{1}$ Fundação Oswaldo Cruz, Belo Horizonte, Minas Gerais, Brazil; ${ }^{2}$ Universidade Federal de Minas Gerais, Belo Horizonte, Minas Gerais, Brazil: ${ }^{3}$ New York University, New York, USA

Introduction The speed of demographic ageing in low and middle income countries has been unprecedented in comparison with Western European and North American countries. However, few studies have examined whether health conditions of the elderly has changed over time in middle and low income countries. We used data from a national health survey to examine 10-year trend (1998-2008) in health conditions of Brazilian elderly.

Methods A nationally representative sample of 105254 individuals aged $\geq 60$ years participated.

Results The mean age was 69 years and $56 \%$ were women. There was a gradual increase on the prevalence of good or excellent selfrated health $(39.3 \%, 43.5 \%$ and $45.0 \%$ in 1998, 2003 and 2008, respectively) and a decrease in self-reported arthritis, heart disease, and depression. The prevalence of self-reported hypertension $(43.9 \%$, $48.8 \%$, and $53.3 \%$, respectively) and diabetes (10.3\%, $13.0 \%$ and $16.1 \%$ respectively) increased gradually. The prevalence of inability to perform activities of daily living (eating, bathing or using the toilet) remained stable $(6.5 \%, 6.4 \%$ and $6.9 \%$, respectively). The achievement of three or more doctor visits increased by $28 \%$ from 1998 to 2003, and 45\% from 1998 to 2008. Hospitalisations (any) decreased in the corresponding period ( $8 \%$ and $12 \%$ respectively). The above mentioned trends remained after adjustments for age and sex

Conclusion The results showed improvements in some health dimensions of the elderly, but not in all. Changes in the use of health services occurred as expected with the expansion of primary healthcare activities in Brazil. 